\title{
MÉTODO PARA PESQUISA SOBRE IDENTIDADE REGIONAL DO ARTEFATO POPULAR SOB A ÓTICA DO DESIGN
}

Maria Beatriz Ardinghi

Universidade de São Paulo

beatrizardinghi@gmail.com

Resumo: Este artigo trata do método utilizado na pesquisa intitulada "Glossário visual popular paulista: artefatos memoráveis presentes em residências de famílias de origem rural no estado de São Paulo", que identificou e analisou do ponto de vista da percepção, uso e significado, um número determinado de artefatos domésticos considerados memoráveis e notáveis em residências de famílias de origem rural no estado de São Paulo, a fim de contribuir para os estudos da cultura material popular brasileira em relação às identidades regionais do objeto brasileiro popular, sob a ótica do design. O procedimento utilizado baseou-se no método da história oral, partindo de entrevistas e coleta de depoimentos informais para a caracterização dos artefatos chamados memoráveis, isto é, que participaram de vivências afetivas da infância de parte da população adulta selecionada. A partir daí, efetuou-se uma pesquisa de campo a fim de se identificar estes artefatos presentes em residências de paulistas idosos de origem rural, distribuídas por regiões representativas do estado de São Paulo, de modo a compor um acervo de artefatos notáveis, fazendo uso de registros fotográficos e entrevistas semiestruturadas para a coleta de dados. Em seguida, foram analisados seus atributos formais e funcionais bem como os significados a eles atribuídos por seus usuários dentro do contexto em que estão inseridos. Por meio desta pesquisa foi possível caracterizar a existência de uma identidade da cultura material popular paulista sob a ótica design, bem como a estreita relação entre esta identidade e sua origem sociocultural e histórica.

Palavras-chave: Identidade cultural; Cultura material; Método de pesquisa; Artefatos de memória

Abstract: This article discuss the method used in the research titled
"Popular visual glossary of São Paulo: memorable artifacts present in
residences of rural origin families in the state of São Paulo", which
identified and analyzed aspects of perception, use and meaning of a
number of domestic artifacts considered memorable that can be found in
rural origin family homes in the state of São Paulo, in order to contribute to
the study of popular material Brazilian culture in relation to regional
identities of the popular Brazilian object, from the perspective of design.
The method used in this study was based on interviews and the collection of 
informal testimonials to characterize what we call memorable artifacts, which are objects that participated in childhood affective experiences of the selected adult population. After that, a field survey was carried out to identify these artifacts present in São Paulo residences of elderly rural origin, spread across representative regions of the state of São Paulo, through photographic records and interviews. Then, it was analyzed their formal and plastic attributes in order to identify a possible regional language of popular household objects and the meanings given to them by their users. Through this research, it was possible to characterize the existence of an identity of São Paulo popular material culture from the design perspective. In addition, it is possible to state that this identity is related to their social, cultural and historical origin.

Keywords: Cultural identity; Material culture; Research methods; Memorable artifacts

\section{INTRODUÇÃO}

Os artefatos são símbolos de uma cultura, carregam significados atribuídos a eles por um determinado grupo de pessoas num dado contexto histórico e sociocultural. Estudar suas características, bem como seus significados, é uma maneira de se compreender os valores, costumes e tradições daquele grupo.

$O$ design, por meio de seus produtos, tem o poder de influenciar diretamente a construção da cultura de um determinado povo. Paradoxalmente, quando se trata de culturas populares, muitos de seus artefatos, resultado de criações anônimas de design espontâneo, apresentam-se como uma forma de resistência dos valores culturais daquele grupo frente a uma situação de submissão econômica e social.

Seguindo este pressuposto, foi realizada uma pesquisa cujo objeto de estudo foram artefatos domésticos de uso cotidiano encontrados em residências de famílias de origem rural no estado de São Paulo, nos dias atuais, que, embora ordinários, representam a cultura material do povo paulista na medida em que habitam não somente as casas da camada subalterna desta sociedade, descendente de sitiantes, caipiras e colonos imigrantes, mas também as memórias de grande parte da população adulta paulista, onde quer que ela se encontre, cujas vivências da infância ocorreram neste contexto na segunda metade do século XX.

Tendo-se em conta estudos da cultura material que advogam "a noção de que os povos e as sociedades se dão a conhecer através dos artefatos que produzem" (CARDOSO, 1998, p. 37), estudar estes objetos foi uma maneira de se investigar aspectos da formação da sociedade no estado de São Paulo, eminentemente rural, com a qual se identifica grande parte da população paulista adulta nos dias atuais. Suas memórias afetivas frequentemente guardam lembranças de tempos na casa da avó, férias com os primos do interior, reuniões em volta da mesa da cozinha com cheiro de fogão a lenha. Essas memórias constituem sua identidade e nos indicaram o caminho para esta pesquisa acerca da cultura material popular paulista e suas tradições.

O objetivo da pesquisa foi contribuir para os estudos da cultura material brasileira em relação à possibilidade da existência de identidades regionais do objeto 
brasileiro popular, sob a ótica do design, através do estudo semiótico de um número determinado de artefatos domésticos considerados memoráveis e notáveis ${ }^{1}$ encontrados em residências de pessoas idosas de origem rural no interior do estado de São Paulo nos dias atuais.

Entendendo o folclore ${ }^{2}$ como uma disciplina que estuda os produtos da mentalidade popular e compreendendo a presença e a maneira de dispor estes objetos no ambiente doméstico, assim como o saber utilizá-los, um resultado da mentalidade destes indivíduos, este trabalho, um estudo de folclore com enfoque no design de artefatos, adotou a abordagem proposta por um dos pioneiros nos estudos em folclore no Brasil, Amadeu Amaral (1921), que defendia que os significados dos fatos folclóricos só poderiam ser compreendidos quando fossem estudados mergulhados em seu contexto sociocultural.

Este artigo tem como objetivo apresentar o método empregado na pesquisa de modo a colaborar com pesquisadores e designers interessados nas questões acerca da identidade cultural no discurso do design e sua relação com as memórias afetivas e a cultura material popular.

\section{DESENVOLVIMENTO}

A pesquisa em questão deve ser entendida como uma pesquisa qualitativa de natureza teórica na modalidade etnográfica, mas com um acentuado caráter fenomenológico, uma vez que sua questão central foi caracterizar a identidade regional do objeto popular, ou seja, a identificação de um possível padrão cultural. Entretanto, seu enfoque foi semiótico, uma vez que, partindo das relações de pessoas com artefatos presentes em suas memórias afetivas, investigou-se os significados destes objetos para um determinado número de pessoas nos dias atuais em um dado contexto, bem como seus aspectos formais e funcionais.

$O$ trabalho se desenvolveu em sete fases distintas, descritas a seguir.

\subsection{Fase I. Conceituação teórica}

A primeira fase consistiu em uma pesquisa bibliográfica sobre os principais conceitos teóricos do projeto - tais como identidade cultural, cultura popular e folclore, e a relação da memória com os objetos -, de modo a fundamentá-lo. Sobre identidade cultural e cultura popular, baseamo-nos principalmente em Hall (2011), Canclini (1983), Arantes (1982), Bosi (1992) e Chauí (1986).

Sobre folclore, Amaral (1976), Brandão (1982), Ortiz (1985).

\footnotetext{
1 Para fins metodológicos, utilizamos os termos artefatos memoráveis e artefatos notáveis como diferenciação em função das fases da pesquisa. Por artefatos memoráveis compreende-se objetos "que fazem bem lembrar" (DAMAZIO, 2005, p. 43), presentes nas memórias afetivas de vivência da infância relatadas em entrevistas e depoimentos espontâneos na fase de identificação do objeto de pesquisa.

O termo artefatos notáveis foi empregado para caracterizar aqueles artefatos memoráveis notados, ou seja, localizados, identificados e registrados em residências de pessoas idosas em cidades de tradição rural no interior do estado de São Paulo, na pesquisa de campo.

${ }^{2} \mathrm{O}$ trabalho considerou equivalentes os termos folclore e cultura popular, de acordo com a definição do Centro Nacional de Folclore e Cultura Popular do Ministério da Cultura, consonante com o que preconiza a UNESCO, e também Arantes (1982) e Brandão (1982).
} 
A relação da memória com os objetos foi ancorada nos estudos realizados por Pollak (1992), Halbwachs (1990), Simson (2003), Baudrillard (2008), Damazio (2005) e Csikszentmihalyi (1991).

\subsection{Fase II. Contextualização histórico-social}

Em seguida, deu-se a contextualização histórico-social e a caracterização de ambiência da pesquisa, ou seja, o estado de São Paulo, seu processo de povoamento, as particularidades de sua origem rural - com a figura do caipira e dos imigrantes - e a formação da sociedade nesta região.

Os principais autores consultados nesta etapa foram Fausto (2008), Setubal (2004) e Stolcke (1994). Especificamente sobre o caipira e os bairros rurais, baseamonos nos estudos desenvolvidos por Cândido (1987), Brandão (1983), De Queiroz (1973).

Para auxiliar na caracterização da cultura material rural de São Paulo, nas últimas décadas do século XIX e primeiras décadas do século XX, foi realizada uma pesquisa documental de obras de reconhecido teor regionalista, romances e livros de contos de Cornélio Pires (1985); Valdomiro Silveira (1975) e José de Alencar (2012).

Para fornecer subsídios visuais de caracterização do universo material da época citada foram feitas pesquisas iconográficas por meio da análise de obras de arte $^{3}$, e visitas a museus e exposições ${ }^{4}$ de objetos do período citado.

\subsection{Fase III. Identificação dos objetos memoráveis}

Após a contextualização da pesquisa, a etapa seguinte consistiu em identificar o objeto de estudo a partir do cruzamento de três parâmetros. Primeiramente, deveriam tratar-se de objetos populares, uma vez que representam a cultura popular em oposição à cultura erudita, ou ainda por serem representativos da camada subalterna da sociedade rural paulista, ou seja, famílias de origem rural formadas por pequenos proprietários de terra brasileiros, descendentes de portugueses, índios, colonos imigrantes ou mesmo, ainda que em menor número, escravos. Em segundo lugar, deveriam se caracterizar como artefatos memoráveis, ou seja, que teriam participado da memória afetiva de uma determinada parcela da população adulta paulista nos dias atuais. Em terceiro, deveriam se tratar de objetos ordinários que participam da vida privada e cotidiana de famílias com as características acima citadas, que eventualmente pudessem ser encontrados em visitas às residências durante a pesquisa de campo.

$\mathrm{Na}$ primeira etapa, a fim de identificarmos um número significativo de artefatos $^{5}$ considerados memoráveis, foram utilizados depoimentos informais e

\footnotetext{
${ }^{3}$ As seguintes obras de arte do pintor Almeida Jr, pertencentes ao acervo da Pinacoteca do Estado de São Paulo foram analisadas: O violeiro (1899) Amolação interrompida (1894), Apertando o lombilho (1895), Estudo para cabeça de caipira (1893), Caipira picando fumo (1893) e Cozinha caipira (1895).

${ }^{4}$ Foram visitados o Museu de História e Folclore Maria Olímpia, em Olímpia, o Museu Casa do Caipira Fazenda Chocolate, em Itu, o Solar da Marquesa de Santos, em São Paulo, e a exposição Modos de morar dos paulistas: 1840-1940, em Limeira. Para a caracterização do universo dos imigrantes colonos, a pesquisa iconográfica se concentrou nos acervos virtuais do Museu da Imigração do Estado de São Paulo, antiga Hospedaria dos Imigrantes, além da visita feita ao Centro Histórico-Cultural de Santa Olímpia, na cidade de Piracicaba, bairro rural formado por colonos Tiroleses.
} 
entrevistas temáticas semiestruturadas com indivíduos paulistas adultos, entre 27 e 58 anos de idade, de família de origem rural e condição socioeconômica pertinente ao caráter popular da pesquisa, previamente selecionados através de um questionário, indagados sobre as memórias afetivas da infância em casa de parentes no interior do estado, bem como os objetos presentes nestas lembranças e os significados atribuídos a estes, o que permitiu sua caracterização do ponto de vista simbólico. O método da história oral foi utilizado por se caracterizar pela utilização da memória como fonte principal, a qual provê material em forma de narrativa, a fim de dar origem à produção de um documento (NEVES, 2003). O resultado ao final desta fase foi uma lista de 77 artefatos memoráveis a serem localizados em uma pesquisa de campo.

\subsection{Fase IV. Localização dos artefatos notáveis}

Esta fase consistiu na busca pelos artefatos memoráveis in loco. Sendo assim, verificou-se sua ocorrência de modo que, ao seu final, fosse possível elencar uma lista de artefatos domésticos típicos da cultura popular paulista, que foram chamados de artefatos notáveis. Para tanto, foi executada uma pesquisa de campo a residências de paulistas idosos, com idade entre 60 e 97 anos, de origem familiar rural e condição social circunscrita ao contexto da pesquisa.

A amostragem da pesquisa de campo foi definida de modo a atingir regiões representativas do desenvolvimento do estado de São Paulo de acordo com os eixos de expansão da lavoura de café, impulsionado pelo desenvolvimento da malha ferroviária no início do século XX. Desta forma, procurou-se dividir a pesquisa pelas regiões representativas da história rural do estado de São Paulo, levando-se em consideração também a incidência dos relatos de memória.

Foram realizadas 20 visitas a residências de paulistas idosos de origem familiar rural e condição social compreendida dentro do contexto da pesquisa, em 9 cidades $^{6}$ do estado de São Paulo.

Foram feitos registros fotográficos destes objetos, bem como do modo de dispô-los no ambiente doméstico, e colhidos depoimentos dos moradores a respeito de sua história pessoal e de sua relação com aqueles utensílios, fazendo uso de gravações em áudio e anotações diretas. Dos 77 artefatos memoráveis, 71 foram observados em campo, sendo que 54 deles foram encontrados em mais de três ocorrências, parâmetro adotado para validar a representatividade da amostra. Desta forma, elaborou-se um acervo com os 54 artefatos notáveis, isto é, aqueles objetos memoráveis localizados, que se pôde notar e identificar (Quadro 1).

\footnotetext{
${ }^{5}$ Optou-se pelo uso do termo artefato para se referir aos objetos de estudo baseando-se na noção de que "objetos feitos ou modificados por seres humanos podem ser agrupados sob o termo artefato" (PROWN, 1993, p. 2, tradução nossa), mesmo quando se trata de um objeto natural como uma samambaia, por exemplo, uma vez que a samambaia aqui citada não se apresenta em sua forma selvagem em meio à natureza, mas sim modificada e resignificada pela ação humana, interesse central da pesquisa.

${ }^{6}$ As cidades onde ocorreram as visitas foram: Monte Aprazível, Rio Claro, Piracicaba, Cerquilho, Botucatu, Limeira, Campinas, Laranjal Paulista e São Luís do Paraitinga.
} 
Quadro 1 - Lista com os 77 artefatos memoráveis dos quais 54 puderam ser notados em mais de três ocorrências durante a pesquisa de campo.

\begin{tabular}{|c|c|c|c|c|c|}
\hline \multicolumn{6}{|c|}{ Artefatos memoráveis e notáveis } \\
\hline 1 & Arranjo de flor artificial & 27 & Cobre-talha & 53 & Espelho de banheiro com moldura abóbora \\
\hline & Toalhinha de crochê & 28 & Relicário/Oratório de santo & 54. & Jarra de leite \\
\hline & Calendário (folhinha) & 29 & Cobre-prateleira & 55 & Toalha de plástico transparente \\
\hline 4 & Vassoura de palha & 30 & Tapetinhos & 56 & Vaso com espada de São Jorge \\
\hline 5 & Vaso de porcelana decorado & 31 & Potes de vidros decorados (bomboniere) & 57 & Torrador de café \\
\hline 6 & Imagem de santo & 32 & Bule de café & 58 & Ralador de galvanizado \\
\hline 7 & Garrafa térmica com café & 33 & Paneleiro & 59 & Peneira de taquara \\
\hline 8 & Porcelanas decoradas desparceiradas & 34 & Samambaia suspensa & 60 & Moringa de barro \\
\hline 9 & Máquina de costura & 35 & Tacho de cobre & 61 & Moedor de milho \\
\hline 10 & Canteiro com ervas/temperos & 36 & Rádio & 62 & Máquina de fazer macarrão \\
\hline 11 & Roseira & 37 & Caneca de ágata & 63 & Lamparina \\
\hline 12 & Pano de prato pintado à mão & 38 & Copo bico de jaca & 64 & Garrafa de vidro bico de jaca \\
\hline 13 & Panela de ferro & 39 & Santa ceia & 65 & Sapateira \\
\hline 14 & Toalha de plástico decorada & 40 & Gaiola com passarinho/papagaio & 66 & Puxa-saco \\
\hline 15 & Filtro de água de barro (talha) & 41 & Prato porcelana enfeite & 67 & Penico \\
\hline 16 & Cortina de renda & 42 & Pilão & 68 & Garrafa d'água de plástico/jarra \\
\hline 17 & Bacia de alumínio & 43 & Copo pra café & 69 & Gamela de madeira \\
\hline 18 & Retrato de santos/Cristo & 44 & Peneira para grãos & 70 & Carrinho de feira \\
\hline 19 & Retratos antigos de parede & 45 & Capa de botijão de gás & 71 & Canivete com cabo de madre-perola \\
\hline 20 & Varal suspenso por bambu & 46 & Colcha /almofada de retalho & 72 & Vaso com árvore da felicidade \\
\hline 21 & Coador de café de pano & 47 & Moedor de café & 73 & Pé de Romã \\
\hline 22 & Bíblia & 48 & Ferro à carvão & 74 & Panela de barro \\
\hline 23 & Caneca de alumínio & 49 & Colcha de crochê & 75 & Lista telefônica \\
\hline 24 & Crucifixo & 50 & Caneca de louça de brinde de festa & 76 & Antigos equipamentos de fazenda \\
\hline 25 & Comigo-ninguém-pode & 51 & Moedor de carne & 77 & Anão de jardim \\
\hline 26 & Fogão a lenha & 52 & Galinho português de previsão do tempo & & \\
\hline
\end{tabular}

Fonte: Elaborado pela autora, com base na pesquisa realizada.

\subsection{Fase V. Análises dos artefatos}

Esta etapa correspondeu às análises dos 54 artefatos de acordo com os dados coletados na pesquisa de campo. Para tanto, definiram-se critérios que permitissem avaliar o objeto em seu contexto, requisito necessário tanto nos estudos em folclore quanto nos estudos em design, entendendo ambos como fenômenos sociais complexos.

Partindo-se do pressuposto de que estes fenômenos são compostos por códigos com os quais os indivíduos constroem sua rede de significados, optou-se por uma análise com enfoque na semiótica, que "ilumina o processo no qual se dá a construção de um sistema de significação" (NIEMEYER, 2003, p. 14). Considerando-se, portanto, o objeto como signo de uma cultura e o design como formulador de mensagem, baseamos o fundamento teórico em dois autores da semiótica, Morris (1970) e Bense (1971).

Porém, a questão sobre como os indivíduos se relacionam com os objetos ao seu entorno também tem sido amplamente discutida pela psicologia. Desta forma, traçou-se um paralelo com o proposto por Norman (2008) em seu trabalho sobre design emocional e sua classificação dos aspectos do design de acordo com o relacionamento dos indivíduos com os artefatos que os rodeiam em seu cotidiano vivido.

Por fim, interessou-nos olhar a questão sob a ótica do design, enquanto aquele capaz de conduzir as funções dos artefatos em relação aos seus usuários. Entretanto, dentre os objetos analisados, pôde-se observar tanto a presença de produtos industriais quanto de objetos artesanais ou mesmo naturais, bem como ao que denominamos design vernacular. Desta forma, buscamos a classificação de Lobach (1981) sobre as funções dos objetos com vistas ao papel do design na interação 
homem-objeto, considerando que a adoção de um método de análise oriundo do universo do design industrial denotaria a intenção desta pesquisa em tratar os artefatos do design independentemente de seu processo produtivo.

Diante disso, ao agruparmos as dimensões e aspectos dos quatro principais autores das três abordagens citadas, foi possível perceber afinidades relativas ao que denominamos uso, significado e percepção dos objetos, termos que foram adotados para nomear as categorias de análise da pesquisa. Vale acrescentar que, adotarmos para fins metodológicos uma nomenclatura própria evidenciou nosso objetivo de não priorizar nenhuma das classificações estudadas e sim abarcar de modo mais abrangente possível os pontos suscitados pelos autores (Quadro 2).

\section{Quadro 2 - Definição teórica para os critérios de análise dos objetos}

\begin{tabular}{|c|c|c|c|c|c|}
\hline \multirow{3}{*}{ 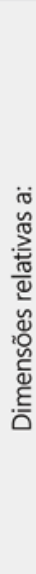 } & $\stackrel{\bigcirc}{\Im}$ & $\begin{array}{l}\text { Função Prática } \\
\text { - aspectos fisiológicos } \\
\text { de uso } \\
\text { - conforto } \\
\text { - segurança }\end{array}$ & $\begin{array}{l}\text { Aspecto Comportamental } \\
\text { - eficácia } \\
\text { - usabilidade } \\
\text { - prazer e facilidade de } \\
\text { operar }\end{array}$ & $\begin{array}{l}\text { Dimensão Pragmática } \\
\text { - utilidade } \\
\text { - padrões ergonômicos } \\
\text { e tecnológicos } \\
\text { - funcionalidade }\end{array}$ & $\begin{array}{l}\text { Dimensão do uso } \\
\text { - pragmática }\end{array}$ \\
\hline & $\begin{array}{l}\text { 은 } \\
\frac{\mathrm{U}}{\mathrm{U}} \\
\frac{\mathrm{U}}{\mathrm{U}}\end{array}$ & $\begin{array}{l}\text { Função Simbólica } \\
\text { - aspectos espirituais } \\
\text { e psíquicos de uso } \\
\text { - relaçōes com } \\
\text { experiências e } \\
\text { sensações anteriores }\end{array}$ & $\begin{array}{l}\text { Aspecto Reflexivo } \\
\text { - significados atribuídos } \\
\text { - particularidades } \\
\text { culturaise individuais } \\
\text { - memória afetiva }\end{array}$ & $\begin{array}{l}\text { Dimensão Semântica } \\
\text { • significaçăo } \\
\text { · representação } \\
\text { • expressão }\end{array}$ & $\begin{array}{l}\text { Dimensão da forma } \\
\text { - semântica }\end{array}$ \\
\hline & 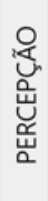 & $\begin{array}{l}\text { Função Estética } \\
\text { - percepçăo } \\
\text { - sensorial } \\
\text { - prazer contemplativo }\end{array}$ & $\begin{array}{l}\text { Aspecto Visceral } \\
\text { - aspectos fisicos } \\
\text { - aparência }\end{array}$ & $\begin{array}{l}\text { Dimensão Sintática } \\
\text { - estrutura do objeto } \\
\text { - elação entre as } \\
\text { partes e com o todo } \\
\text { - amposiçăo formal }\end{array}$ & $\begin{array}{l}\text { Dimensão técnica } \\
\text { ou construtiva } \\
\text { - sintaxe } \\
\text { Dimensão Material } \\
\text { - hílico }\end{array}$ \\
\hline & & Lobach & Norman & Morris & Bense \\
\hline
\end{tabular}

Fonte: Elaborado pela autora, com base na pesquisa realizada.

Desta maneira foram criadas três fichas de análise para as dimensões percepção, significado e uso, com categorias e subcategorias específicas, às quais foram submetidos os 54 artefatos. As categorias investigadas dentro das três dimensões - percepção, significado e uso - foram definidas, primeiramente, baseandose em uma análise piloto da amostra e de acordo com os dados coletados nas entrevistas. Observando as imagens dos artefatos e as anotações feitas durante as visitas às residências, listamos características materiais relativas a formas, cores e acabamentos, por exemplo. Em relação aos aspectos simbólicos e funcionais, selecionamos termos inseridos nos depoimentos, além de anotações feitas pela pesquisadora observando os entrevistados utilizarem alguns dos artefatos durante as visitas, de forma a criar as subcategorias a serem analisadas.

Uma quarta ficha relativa à forma de aquisição dos artefatos acabou por ser criada de modo a organizar estes dados, uma vez percebida a relação entre o significado do objeto para seu usuário e o modo ou o local onde este artefato foi adquirido, por exemplo, se foi comprado, presente ou herança.

Deste modo, submetendo os objetos às fichas de análise (Quadro 3), foi possível observar de forma sistemática e abrangente os objetos, sua materialidade, sua composição como um todo e as partes que os compõem, seus detalhes visuais e construtivos, bem como as relações destes artefatos com seus usuários, tanto 
operacionais, isto é, relativas à sua funcionalidade, quanto simbólicas, o que compreende os significados atribuídos a eles pelos indivíduos.

Quadro 3 - Modelo de ficha criada para a análise dos objetos relativa à dimensão percepção.
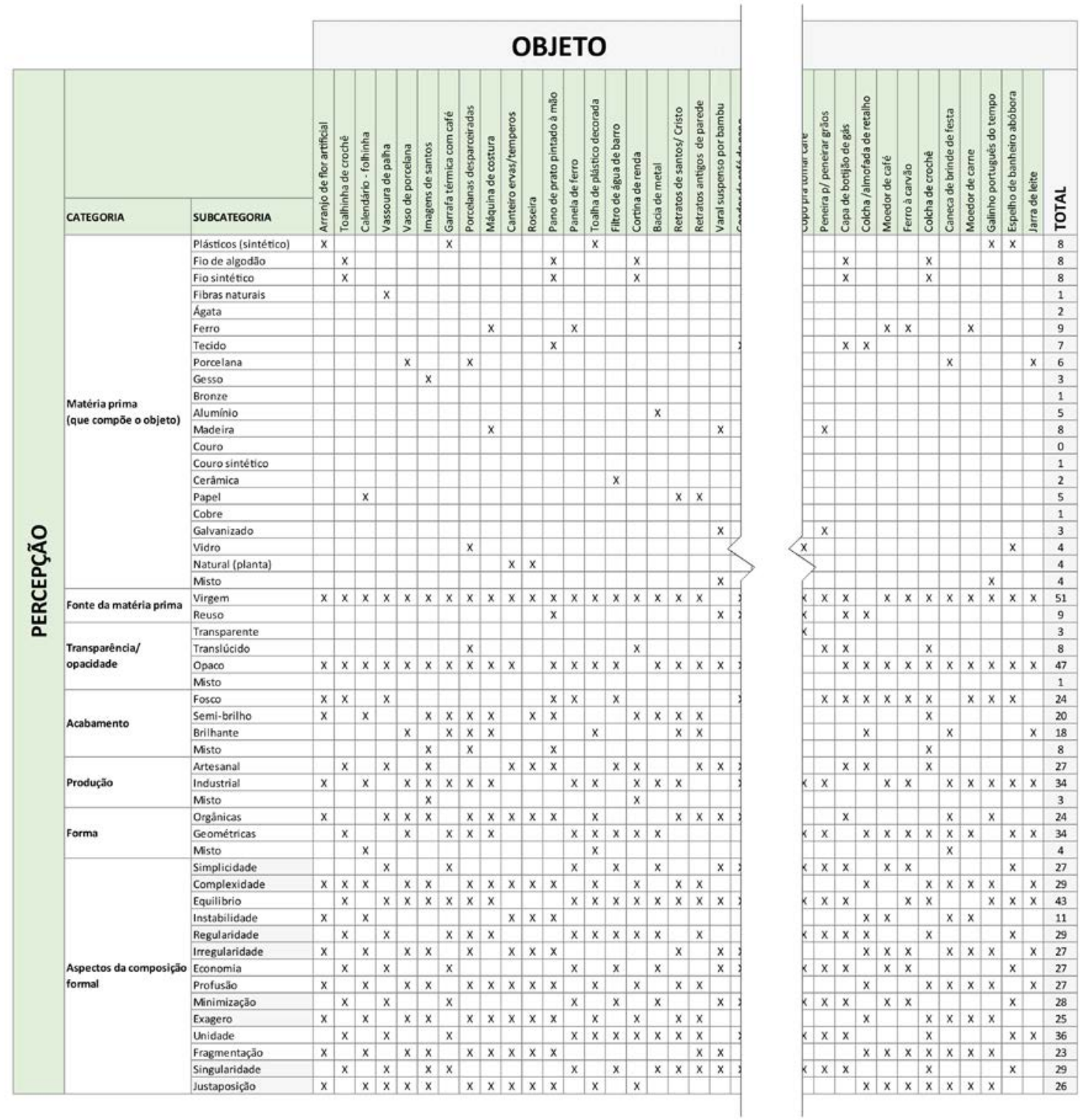

Fonte: Elaborado pela autora, com base na pesquisa realizada.

\subsection{Fase VI. Confrontação}

De posse de imagens fotográficas dos artefatos notáveis encontrados na pesquisa de campo, voltamos aos adultos respondentes cujas memórias de infância constituíram a base para a pesquisa, a fim de confrontar as imagens capturadas no campo com suas lembranças.

O resultado deste confronto nos trouxe extenso material sobre a relação do indivíduo com sua origem e sua identidade versus sua noção estética sobre aqueles artefatos. Os depoimentos colhidos nesta fase propiciaram-nos uma reflexão sobre as inter-relações culturais, sobre as diferenças de padrões estéticos entre gerações de uma mesma família, e demais considerações para um possível artigo específico ao tema. 


\subsection{Fase VII. Discussão dos resultados}

Finalmente a sétima e última fase do trabalho compreendeu a discussão dos resultados obtidos nas análises. Os campos das fichas de análise foram transformados em dados visuais (Figura 1) e agrupados de acordo com possíveis padrões de semelhança em relação aos atributos investigados de modo a configurar aspectos da linguagem destes objetos, objetivo central do trabalho.

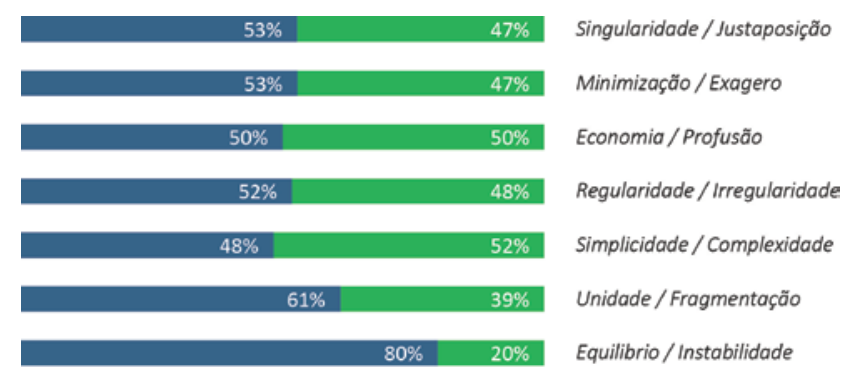

Figura 1 - Aspectos da composição formal dos objetos denota dois grupos distintos e equilibrados Fonte: Elaborada pela autora, com base na pesquisa realizada.

Como exemplo do processo executado, tomemos a Figura 1 onde os dados apresentaram dois grupos distintos e equilibrados do ponto de vista da composição formal dos objetos, e o correspondente quadro de imagens fotográficas de alguns dos artefatos estudados (Figura 2).
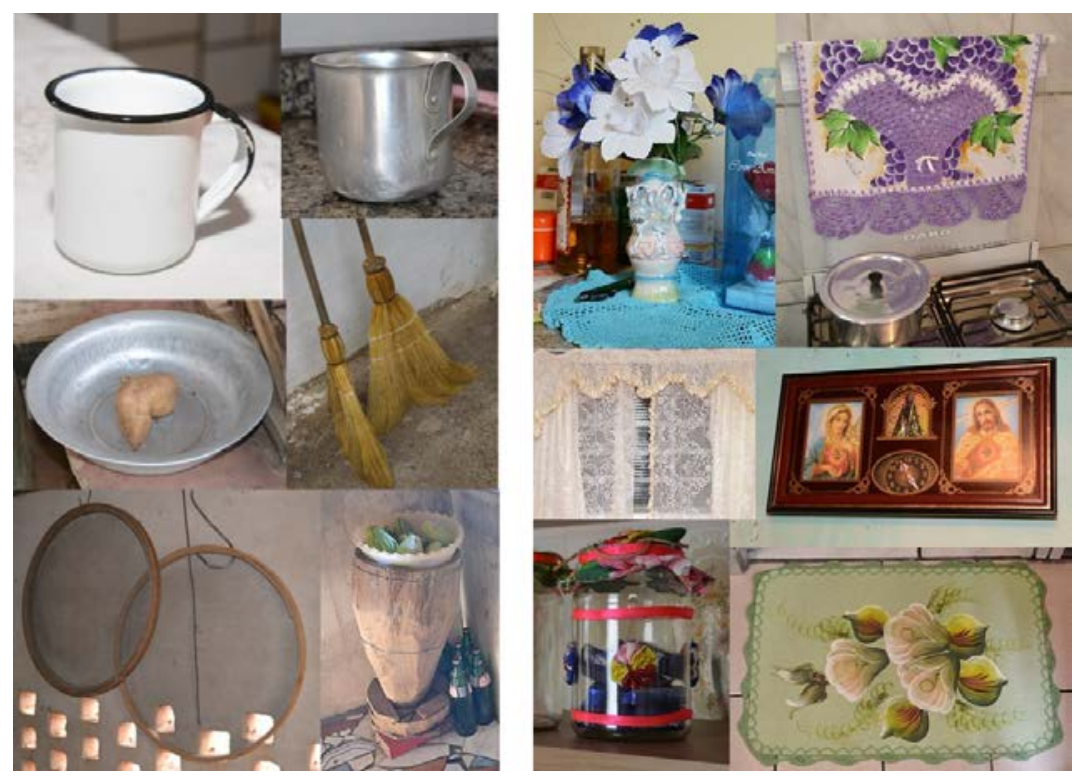

Figura 2 - À esquerda, universo formal simples: caneca de ágata, bacia de alumínio e vassoura de palha; à direita, objetos decorados: tapete pintado à mão, pano de prato bordado e cortina de renda. Fonte: Elaborada pela autora, com base na pesquisa realizada.

À esquerda aparecem os objetos formalmente muito simples, relacionados a atributos como simplicidade, regularidade, economia, minimização, unidade $e$ singularidade. Cruzando-se as informações da ficha de análise de percepção com a de uso, notou-se que este grupo de objetos simples do ponto de vista formal está vinculado a categorias de uso especificamente voltadas ao desempenho funcional do artefato como limpeza, ou preparo/cultivo de alimentos e bebidas.

Acrescentando-se à análise os dados relativos ao significado dos artefatos, pôde-se depreender que o grupo formalmente simples se relaciona com as categorias 
hábito/costume/segurança, origem/tradição rural ou ainda com a categoria sem significado relacionado. Com relação à forma de aquisição destes objetos, o destaque ficou em relação à ocorrência de objetos na categoria herança.

À direita aparece o segundo grupo formado por objetos carregados de informação visual que correspondem a atributos como complexidade, instabilidade, irregularidade, profusão, exagero, fragmentação e justaposição e se relacionam com atributos de uso tais como enfeitar a casa, proteger um móvel/piso e oferenda/culto religioso. Com relação aos dados relativos ao significado, os artefatos ricamente decorados se relacionam com as categorias devoção/fé/crença religiosa, cuidado/capricho com a casa, habilidades manuais tipicamente femininas e amor familiar. E quanto à forma de aquisição, aparecem mais frequentemente as categorias presente e produzido pelo morador(a).

Deste modo, cruzando-se os dados obtidos nas análises com as imagens e depoimentos coletados nas residências foi possível identificar, além de semelhanças, particularidades de ocorrências individuais, compreendendo-se que uma determinada identidade também possa se caracterizar por meio de diferentes unicidades.

\section{CONCLUSÃO}

Vários indícios nos permitem afirmar que os artefatos encontrados representam a herança da cultura caipira miscigenada com a cultura dos imigrantes que conviveram, e ainda convivem, lado a lado, nas residências. Os aspectos estudados, ou seja, as características de uso e de percepção destes artefatos, bem como os significados a eles atribuídos, apontaram-nos uma determinada identidade no design intimamente ligada à sua origem sociocultural, portanto histórica.

Do ponto de vista da utilização de materiais, foram encontrados tanto artefatos rústicos e artesanais - como uma peneira de taquara ou um pilão de madeira provenientes da cultura indígena e, posteriormente, caipira -, como objetos de ferro fundido, herança dos europeus - como panelas e moedores de grãos ou de carne e o ferro a brasa para passar roupa.

A escassez de recursos e de bens materiais característica da cultura dos caipiras nômades e da maioria dos imigrantes que veio trabalhar nas lavouras de café, privados da posse das terras e obrigados a sobreviver com o que Candido (1987) chamara de mínimos vitais, pode ser reconhecida em duas circunstâncias. Primeiramente, notou-se uma confirmação desta situação em relação à economia de certos recursos, ao hábito segundo o qual não se joga nada fora, não se desperdiçam materiais ou sobras, reaproveitam-se velhos objetos ou sobras para a produção de novos. Em segundo lugar, percebeu-se uma negação daquela condição vivida por seus antepassados, como um tipo de compensação por tempos difíceis enfrentados por seus parentes: em oposição ao mínimo vital, encontramos fartura, principalmente em relação às atividades e utensílios voltados à preparação de alimentos. Estas tarefas são consideradas compensadoras e repletas de significados extrínsecos, vistas como um sinal de amor tanto pelos idosos entrevistados quanto pelos relatos das memórias dos adultos respondentes.

A família continuou a justificar a noção de unidade autônoma de produção, herança dos bairros rurais caipiras, distantes do centro e das vilas. Ainda se produz dentro das casas uma grande variedade de objetos e alimentos, desde vassouras de 
palha até toalhas de crochê, e as habilidades manuais são passadas para as gerações futuras de modo a garantir a transmissão destes saberes. A casa como uma unidade autônoma também pode ser percebida em relação à religiosidade na manutenção do ritual religioso doméstico com altares e relicários dedicados a santos.

A maioria das tarefas domésticas continua, também aos moldes de seus antepassados, a cargo das mulheres. A dedicação e a competência com que executamnas, apesar de reconhecidas entre as próprias mulheres por meio de elogios e mesmo com uma certa reverência - como a determinadas receitas que só a avó sabe fazer ou um ponto de crochê de difícil execução - não são traduzidas como um valor no núcleo familiar. Esta situação, relatada por Stolcke (1994) em seus estudos sobre os sistemas de trabalho e a estrutura familiar dos imigrantes italianos nas fazendas do café em São Paulo no início do século $X X$, pode ser verificada quase um século depois.

As práticas vicinais de mutirões dos caipiras podem ser observadas, mas não mais na lida com a terra, uma vez que o trabalho no campo passou a ser assalariado. Porém, a ajuda mútua entre mulheres de uma determinada comunidade, comprando toalhinhas de crochê no bazar da igreja apenas com a intenção de ajudar a arrecadar fundos para esta ou aquela causa que considera válida, foi um bom exemplo do espírito comunitário que resistiu ao tempo, se conectando com a prática de camaradagem entre vizinhos típica dos caipiras.

Acreditamos que esta materialidade foi resultante da herança histórica dos povos e do processo de formação da sociedade rural em São Paulo. Para isso, contribuíram: a pobreza da capitania de São Vicente no início da colonização do Brasil; o bandeirantismo e a miscigenação de portugueses e índios; o nomadismo e a falta de posse da terra; os caipiras, seus hábitos e valores; e a convivência com os imigrantes europeus vindos para trabalhar nos latifúndios de café.

Por questões metodológicas, restringimos a extensão geográfica desta pesquisa ao estado de São Paulo. Mas é preciso compreender que o foco do estudo se deu pelo viés sociológico, por meio da cultura caipira, e não pelo cartográfico. Deste modo, acreditamos ser possível assumir que esta materialidade típica do paulista também se encontra presente em grande parte do sul do estado de Minas Gerais bem como no norte do Paraná, onde a cultura caipira também é, historicamente, muito presente. Para comprovarmos esta hipótese, seria necessário replicarmos o método aqui empregado nas regiões acima citadas, o que poderia caracterizar uma continuidade deste estudo. Instiga-nos replicar o método aqui empregado também em outras regiões do país, cujas sociedades sejam oriundas de outros povos e processos de formação, o que poderia resultar em um novo glossário visual típico destes locais. Deste modo talvez seja possível tecermos uma grande colcha de retalhos de identidades regionais, chegando a uma compreensão mais ampla e profunda do artefato popular brasileiro.

\section{REFERÊNCIAS}

AMARAL, A. Tradições populares. 2. ed. São Paulo: Hucitec; Secretaria da Cultura, Ciência e Tecnologia, 1976.

ALENCAR, J. Til. 2. ed. São Paulo: Martin Claret, 2012.

ARANTES, A. A. O que é cultura popular. 3. ed. São Paulo: Brasiliense, 1982.

BAUDRILLARD, J. O Sistema dos Objetos. 5. ed. São Paulo: Perspectiva, 2008. 
BOSI, A. Dialética da colonização. São Paulo: Companhia das Letras, 1992.

BRANDÃO, C. R. O que é folclore. São Paulo: Brasiliense, 1982.

. Os caipiras de São Paulo. São Paulo: Brasiliense, 1983.

CANCLINI, N. As culturas populares no capitalismo. São Paulo: Brasiliense, 1983.

CANDIDO, A. Os parceiros do Rio Bonito. 7. ed. São Paulo: Livraria Duas Cidades, 1987.

CARDOSO, R. Design, cultura material e o fetichismo dos objetos. Arcos, v. 1, 1998.

CHAUÍ, M. Conformismo e resistência, aspectos da cultura popular no Brasil. São Paulo: Brasiliense, 1986.

CSIKSZENTMIHALYI, M. Design and Order in Everyday Life. Design Issues, Cambridge, v. 8, n. 1, p. 26-34, outono, 1991. Disponível na internet por: <http://www. jstor.org /stable/ 1511451>. Acesso em: 12 abr. 2013.

DAMAZIO, V. Artefatos de Memória da Vida Cotidiana: um olhar interdisciplinar sobre as coisas que fazem bem lembrar. Tese de Doutorado em Ciências Sociais - UERJ, Rio de Janeiro, 2005.

DE QUEIROZ, M. I. P. Bairros rurais paulistas, dinâmica das relações bairro ruralcidade. São Paulo: Duas Cidades, 1973.

FAUSTO, B. História concisa do Brasil. São Paulo: Edusp, 2008.

HALBWACHS, M. A memória coletiva. São Paulo: Vértice; Editora Revista dos Tribunais, 1990.

HALL, S. A identidade cultural na pós-modernidade. Rio de Janeiro: DP\&A, 2000.

LÖBACH, B. Design industrial: bases para a configuração dos produtos industriais. São Paulo: Blucher, 2001.

MORRIS, C. W. Foundations of the theory of signs. Chicago: The University of Chicago Press, 1970.

NEVES, L. de A. Memória e História: potencialidades da História Oral. Revista ArtCultura, v. 5, n. 6, p. 27-38, 2003.

NIEMEYER, L. Elementos de semiótica aplicados ao design. Rio de Janeiro: 2AB, 2003.

NORMAN, D. A. Design emocional: por que adoramos (ou detestamos) os objetos do dia-a-dia. Rio de Janeiro: Rocco, 2008.

ORTIZ, R. Cultura brasileira e identidade nacional. São Paulo: Brasiliense, 1985.

PIRES, C. Musa Caipira e As Estrambóticas Aventuras do Joaquim Bentinho. Tietê, SP: Prefeitura de Tietê, 1985.

POLLAK, M. Memória e identidade social. Estudos Históricos, Rio de Janeiro, v. 5, n. 10, 1992.

PROWN, J. D. The truth of material culture: history or fiction? In: LUBAR, Steven; KINGERY, W. David (Eds.) History from things: essays on material culture. Washington: Smithsonian: 1993. p. 1-19. 
SETUBAL, M. A. (Coord.) Modos de Vida dos paulistas: identidades, famílias e espaços domésticos. Centro de Estudos e Pesquisa em Educação, Cultura e Ação Comunitária. São Paulo: CENPEC; Imprensa Oficial do Estado de São Paulo, 2004.

SILVEIRA, V. Os caboclos, contos. 2. ed. Rio de Janeiro: Civilização Brasileira, 1975.

Leréias: histórias contadas por eles mesmos, contos. 2. ed. Rio de Janeiro: Civilização Brasileira, 1975.

Muxuangos, contos. 2. ed. Rio de Janeiro: Civilização Brasileira, 1975.

SIMSON, O. R. M. V. Memória, cultura e poder na sociedade do esquecimento. Augusto Guzzo Revista Acadêmica, n. 6, p. 14-18, 2003.

STOLCKE, V. A família que não é sagrada - Sistemas de trabalho e Estrutura familiar: o Caso das Fazendas do café em São Paulo. In: ARANTES, A. A. et al. Colcha de retalhos: estudo sobre a família no Brasil. Campinas: Unicamp, 1994. p. 72-79. 